\title{
The 150th anniversary of the first depiction of the lesions of multiple sclerosis
}

\author{
ALASTAIR COMPSTON \\ From the Department of Neurology, University of Wales College of Medicine, Heath Park, Cardiff, UK
}

SUMMARY The clinical and pathological features of multiple sclerosis were fully described, in France and subsequently in England, during the latter half of the XIXth century but clinical descriptions, personal accounts and depictions of the disease had appeared at various times over the previous 50 years. Jean Cruveilhier is usually credited with having first illustrated the lesions of multiple sclerosis in the second tome of his pathological atlas which bears the title date 1835 . But the 40 livraisons which make up this work were published separately in parts and documentary evidence contained within the second volume indicates that the putative case of multiple sclerosis cannot have appeared earlier than 1841. Robert Carswell also may have published his pathological atlas in parts but the work was completed by 1838 and so his depiction of the lesions of multiple sclerosis, appearing on plate 4 fig 1, predates Cruveilhier's by at least three years. Curiously, Carswell and Cruveilhier each observed their pathological material in Paris but they cannot have depicted the same individual. 1988 is therefore the 150th anniversary of the depiction of the lesions of multiple sclerosis; the unnamed patient was French, the illustrator a Scotsman.

Is 1988 the 150 th anniversary of the first depiction of the lesions of multiple sclerosis or should the occasion have been celebrated three years ago? Jean Charcot was aware of patients with multiple sclerosis in whom symptoms had begun in or before 1856 , from at least $1859{ }^{1}$ he gathered together the early descriptions so effectively, adding his own clinical and pathological observations, ${ }^{2}$ that the condition was named eponymously after him by Julius Althaus in 1877. By this time the disease was already well known to neurologists working in the United Kingdom, the Lancet having anonymously published case reports on 15 February 1873 and 3 April, 17 April and 1 May $1875 .^{3-6}$ All but one of these patients was under the care of Dr William Moxon at Guys Hospital and they can be identified from his report in full of eight cases which, appearing in $1875,{ }^{7}$ forms the first full description of multiple sclerosis in the English medical litera-

\footnotetext{
Address for reprint requests: Prof D A S Compston, Department of Neurology, University of Wales College of Medicine, Heath Park, Cardiff CF4 4XN, UK.
}

Received 1 March 1988. Accepted 15 April 1988 ture. But if Charcot was authoritative in his overall handling of the disease, he was less careful in outlining its history.

The diagnosis of multiple sclerosis can retrospectively be made from a clinical description given by CP d'Angieres Ollivier in his monograph on diseases of the spinal cord, published in $1824^{8}$ (Ebers, personal communication), and it has been suggested that John Abercrombie described a case in his "Pathological and Practical Researches on Diseases of the Brain and Spinal Cord"9 but this is not readily identifiable from the pathological material contained in any editions of the book. As is well known, a manuscript diary kept by Augustus D'Este (grandson of George III) between 1822 and 1848 and his almanac for 1847-8 were rediscovered in 1942 and placed permanently on loan to the Royal College of Physicians in London. The diary was published with a commentary by Dr D Firth in $1948 .^{10}$ After studying at Harrow School, where he contracted measles on 26 February 1808, D'Este joined the VIIth Royal Fusiliers in 1812 and eventually reached the rank of lieutenant colonel. The surviving part of his diary starts with a description of bilateral optic neuritis which developed in 1822 and 
recurred in 1826; he had episodes of diplopia and weakness in the legs with perineal numbness in 1827 , after which he was never able to run fast or dance. During 1828 he had unpleasant sensory symptoms and fatigue but continued with his military career until developing urinary retention; he became constipated, had a single episode of faecal incontinence, and whilst visiting Ramsgate discovered that he was impotent. Thereafter the diary contains accounts of visits to European Spas, opinions given and treatment suggested. Presumably missing parts document other events for by 1843 D'Este was ataxic, numb below the waist and had spasms at night; in that year he had an episode consistent with brain stem demyelination which partially recovered but before long he was well established on a chronic progressive course with superimposed relapses later becoming paralysed, losing the use of his arms and eventually dying in December 1848, after having had symptoms intermittently for 26 years. Until this record was published, the best known personal account of multiple sclerosis was that recorded by the frustrated zoologist $\mathrm{BF}$ Cummings and published on 31 March 1919 under the pseudonym WNP Barbellion as "The Journal of a Disappointed Man". ${ }^{11}$

It is against this background that the first depiction of the lesions of multiple sclerosis should be considered. Nowadays, Jean Cruveilhier's 'Anatomie pathologique du corps humain etc' is usually found in two volumes bearing the title dates 1835 and 1842 , respectively; ${ }^{12}$ the separate livraisons had started to appear from 1829 accounting for variation in the date given for publication of Cruveilhier's illustrations of multiple sclerosis. Volume I contains livraisons 1-20, and volume 2 numbers $21-40$. Livraison 32 plate 2 and livraison 38 plate 5 , both in volume 2 , are thought to depict the lesions of multiple sclerosis; their publication cannot have been earlier than 1835 , the date cited by Charcot and others. The rival claim for priority is Robert Carswell's Pathological Anatomy; Illustrations of the Elementary Forms of Disease published in $1838^{13}$ in which plate 4 fig 1 shows "a peculiar diseased state of the cord and pons varolii", which modern commentators have interpreted as representing the macroscopical appearances of the plaques seen in multiple sclerosis. Charcot wrote (in the English translation by George Sigerson) "disseminated sclerosis is mentioned for the first time in Cruveilhier's Atlas d'anatomie pathologique, 1835-42.... in parts 22 and 23 you will observe representation of the lesions found in disseminated sclerosis and side by side you can read the clinical observations which relate to them ..... Previous to this epoch, so far as I am aware, there is no trace of disseminated sclerosis to be discovered anywhere. After Cruveilhier, Carswell in the article on "atrophy" contained in his "atlas", 1838, has had lesions depicted which pertain to multiple sclerosis". Charcot's citations do not follow the collation of Cruveilhier's atlas in any personally examined copies.

Robert Carswell studied medicine at the University of Glasgow and was later commissioned by Dr John Thompson of Edinburgh to make a collection of drawings illustrating morbid anatomy in connection with which he spent 1822-3 at hospitals in Lyon and Paris. He returned to Paris after graduating MD in 1826 and remained there until 1831 by which time he had been appointed to the inaugural chair of pathology at London University; but for a while he remained studying with Louis in France in order to complete the 2000 water colours of pathological specimens which he later personally engraved on stone in preparation of his pathological atlas. After holding appointments as physician at University College Hospital he resigned his chair in 1840 and contributed little more to science prior to his death in 1857 . We do not know the names of the patients with multiple sclerosis depicted by Carswell and he never saw them in life; one was under the care of $M$. Louis in the hospital of La Pitié and the other under M. Chomel at $\mathrm{La}$ Charité but the dates and duration of illness are not known. In the preface to the atlas, dated 15 December 1837, Carswell indicates that he intended 12 fascicles to be included and implied that these had been produced serially; instructions to the binders show that the order of production was the reverse of that in which the fascicles would appear in book form so that the section on "atrophy", which appears fourth and contains the depictions of multiple sclerosis, was evidently one of the last to be prepared.

The legend to plate 4 , fig 4 reads "FF.Isolated points of the pons varolii of a yellowish brown colour; GGG.Patches of the same kind on the spinal cord, all of them occupying the medullary substance which was very hard, semi transparent and atrophied. The atrophy was more conspicuous in some points than in others and is particularly well seen in the figure at $\mathrm{H}$ where it affects the right olivary body; $K$ softening of a portion of the cord. Figure 4, A and B, represent transverse sections of the cord to show that the discolouration commences on the surface of the white and extends inwards to the grey substance". In the accompanying text Carswell wrote "I have met with two cases of a remarkable lesion of the spinal cord accompanied with atrophy. One of the patients was under the care of M. Chomel in the hospital of La Charite; both of them affected with paralysis. I did not see either of the patients but I could not ascertain that there was anything in the character of the paralysis or the history of the cases to throw any light on the nature of the lesion found in the region of the spinal cord. I have represented the appearances observed in 
one case in plate 4 (fig 4)". The cases illustrated by Carswell were therefore observed by him not later than 1831 and published in 1838 but they may have first appeared in a separate fascicle produced in 1837 .

Jean Cruveilhier, born in Limoges in 1791, elected to study medicine under Dupuytren in Paris soon after entering the priesthood; he graduated in 1811. Twice he failed to secure appointments as surgeon to the City Hospital in Limoges, despite meanwhile having taken the chair of operative surgery in Montpellier; he was appointed in 1825 to the professorship of anatomy in Paris. Subsequently he was the first to hold the chair of pathology at the faculty of medicine, provision for which had been made in Dupuytren's will. He remained in Paris benefitting from the material at the Salpétrière and the Musée Dupuytren until the siege of Paris when he moved to his country estate at Succac near Limoges, dying there in 1874 aged 83 years.

Surviving copies of Cruveilhier's atlas exist either with the livraisons bound sequentially by number, each containing a heterogenous collection of plates and clinical descriptions, or rearranged by subject with the plates interleaved in varying order presumably at the whim of individual collators or as a separate volume. The case illustrated in livraison 32 , plate 2, figs 1 and 2 had died in la Salpétrière but the name, dates and details are not given. In fig 3 is shown the case of Madame Gruyer, a 43 year old embroiderer who had a severe movement disorder, likened to chorea. She spent 2 years as a patient at L'Hôpital Necker under the care of Laennec and 10 years at La Salpétrière. Figures 4 and 5 depict the brains and spinal cords of Maurice, for whom no clinical details are given, and Darges (aged 37) whose clinical condition was that of a pseudobulbar palsy. In seeking to establish the date of publication of this livraison some importance should be attached to the case of femme Cherpin in whom the lesions illustrated do not resemble those of multiple sclerosis (fig 6); she occupied bed number 8 in St Gabriel ward up until at least 15 September 1838 . The text of livraison 32 also mentions another patient alive on 30 November 1838 and cites a publication dated 1839. This dates the appearance of livraison 32 as not earlier than 1839 . Livraison 38, plate 5, illustrates the case of Josephine Paget who was blind, paraplegic and had severe proprioceptive sensory loss mimicing locomotor ataxia. She was in bed 16 of St Joseph ward at La Charité on 4 May 1840 and died on 20 March 1841. Another patient described in this livraison was alive in August 1841, and Marshall Hall's Diseases and Derangements of the Nervous System published in 1841 is also cited in the text. Based on the clinical details provided it would be difficult to accept the cases described in livraison 32 as having multiple sclerosis; the evidence is more compelling for Josephine Paget but the details of her case, and therefore livraison 38 itself, cannot have been published prior to 1841 .

It is likely that Carswell and Cruveilhier met at some stage in Paris between 1826-31 when the former returned to London. It seems coincidental that two pathologists working from the same pool of material in the same city at the same time should independently have described a new disease. Although there is a striking similarity in the distribution of lesions affecting the pons illustrated by Carswell and by Cruveilhier in livraison 38 plate 5, Josephine Paget was alive at the time of publication of Carswell's atlas so that it cannot be the same case illustrated in each pathological work.

But there is a third candidate for priority in the depiction of the lesions of multiple sclerosis; in Fielding Garrison's short essay on the history of neurology, updated and considerably extended by Laurence McHenry ${ }^{14}$ priority is claimed for Robert Hooper in his Morbid Anatomy of the Human Brain which contains lithographs based on 4000 necropsies carried out by him at the St Marylebone Infirmary in London over a period of 30 years prior to publication of his work in $1826 .{ }^{15} \mathrm{McHenry}$ comments that plate 4 in Hooper's work shows "a peculiar state of the cord and pons varolii accompanied with atrophy of the discoloured portion" illustrating the lesions of multiple sclerosis, and others agree. But all are mistaken; plate 4 from Hooper's work shows a view of the base of the brain from a case of meningitis and it is in fact Carswell's plate 4 that is being described. Hooper's plates first appeared as a series of folio sheets in 1826; some copies of his Morbid Anatomy etc have this title date but there appears to have been a further edition in 1828; however there are no differences between the texts and plates included in each issue. None of Hooper's 15 published plates shows lesions resembling multiple sclerosis. Not all Hooper's plates were published; item 7574 in the Bibliotheca Osleriana ${ }^{16}$ consists of Hooper's published and unpublished manuscript drawings and lithographs; these "were bequeathed to" the Medical Faculty of McGill University, Montreal but the archive does not appear to contain any illustration suggestive of the lesions of multiple sclerosis.

But if Guys Hospital can take credit for priority in the description of multiple sclerosis in the English language, not all its physicians were uncontaminated by the "French disease". Sir Samuel Wilks writing in 1878 was at pains to point out that "I myself had observed years ago scattered patches of deposit in the cerebrospinal centres, but had failed to associate them with any special form of malady; subsequently Charcot described this sclerosis, disseminated throughout the cord, with the prevailing symptoms 
which accompany it". ${ }^{17}$ Multiple sclerosis was first depicted 150 years ago; the unnamed patient was French, the illustrator a Scotsman.

\section{References}

1 Babinski J. Etude anatomique et clinique sur la sclerose en plaques. Paris, Masson: 1885:95.

2 Charcot JM. Histologie de la sclerose en plaques. $G a z$ Hop (Paris) 1868;41:554-5, 557-8, 566.

3 Anon. Guy's Hospital. Case of insular sclerosis of the brain and spinal cord (under the care of Dr Moxon). Lancet 1873;i:236.

4 Anon. Guy's Hospital. Two cases of insular sclerosis of the brain and spinal cord. Lancet 1875;i:471-3.

5 Anon Report on Clinical Society of London. Lancet 1875;i:545.

6 Anon. Guy's Hospital. Two cases of insular sclerosis of the brain and spinal cord. Lancet 1875;i:609.

7 Moxon W. Eight cases of insular sclerosis of the brain and spinal cord. Guy's Hospital Reports. 1875; 20:437-78.

8 D'Angieres Ollivier CF. De la moelle epinière et de ses maladies. Paris, Crevot 1824.

9 Abercrombie J. Pathological and Practical Researches on
Diseases of the Brain and Spinal cord. Edinburgh: Waugh and Innes, 1828.

10 Firth D. The Case of Augustus D'Este. Cambridge, at the University Press. 1948.

11 Barbellion WNP. The Journal of a Disappointed Man. London: Chatto and Windus. 1919.

12 Cruveilhier J. Anatomie pathologique du corps humain descriptions avec figures lithographiées et coloriées; des diverses alterations morbides dont le corps humain est susceptible. Paris: JB Bailliere. 1835-42.

13 Carswell R. Pathological Anatomy; Illustrations of the Elementary Forms of Disease. London: Longman, Orme, Brown, Green and Longman. 1838.

14 McHenry L. Garrison's History of Neurology. Springfield: CC Thomas. 1969:253-4.

15 Hooper R. The Morbid Anatomy of the Human Brain. Illustrated by coloured engravings of the most frequent and important organic diseases to which that viscus is the subject. London: Longman, Rees, Orme, Brown and Longman. 1828.

16 Osler W. Bibliotheca Osleriana. A catalogue of Books illustrating the History of Medicine and Science collected, arranged, and annotated by Sir William Osler, Bt. and bequeathed to McGill University. Oxford; at the Clarendon Press. 1929:675-6.

17 Wilks S. Lectures on Diseases of the Nervous System. London: Churchill, 1878:282. 